\title{
Avaliação da influência da incorporação do óleo de coco em membranas de Celulose
}

\section{Bacteriana}

\author{
Evaluation of the influence of incorporation of coconut oil in Bacterial Cellulose Membranes \\ Evaluación de la influencia de la incorporación de aceite de coco en las membranas de Celulosa
}

Bacteriana

Recebido: 14/01/2021 | Revisado: 18/01/2021 | Aceito: 22/01/2021 | Publicado: 30/01/2021

\author{
Girlaine Santos da Silva \\ ORCID: https://orcid.org/0000-0002-1379-0297 \\ Universidade Federal de Pernambuco, Brasil \\ E-mail: lane_santos13@hotmail.com \\ Felipe Cunha da Silva Trindade \\ ORCID: https://orcid.org/0000-0002-9368-6608 \\ Universidade Federal de Pernambuco, Brasil \\ E-mail: felpscunha@gmail.com \\ Karina Carvalho de Souza \\ ORCID: https://orcid.org/0000-0002-9902-7566 \\ Universidade Federal de Pernambuco, Brasil \\ E-mail: karinacar_souza@hotmail.com \\ Viviane Fonseca Caetano \\ ORCID https://orcid.org/0000-0002-8517-8312 \\ Universidade Federal de Pernambuco, Brasil \\ E-mail: viviane_fc@yahoo.com.br \\ Yêda Medeiros Bastos de Almeida \\ ORCID: https://orcid.org/0000-0003-1041-7144 \\ Universidade Federal de Pernambuco, Brasil \\ E-mail: lane_santos13@hotmail.com \\ Glória Maria Vinhas \\ ORCID: https://orcid.org/0000-0001-5073-609X \\ Universidade Federal de Pernambuco, Brasil \\ E-mail: gmvinhas@yahoo.com.br
}

\begin{abstract}
Resumo
A celulose bacteriana é um polissacarídeo extracelular nanofibrilar que pode ser produzido por bactérias acéticas. Esse biopolímero apresenta excelentes características, dentre elas tem-se alta cristalinidade, atoxidade, alta pureza, alta resistência à tração, alta capacidade de retenção de água, biocompatibilidade e biodegradabilidade. A adição de óleo vegetal na matriz desse biopolímero surge como uma possibilidade de promover uma diminuição da cristalinidade e ampliar suas aplicações nas mais diversas áreas, principalmente alimentícia e médico-hospitalar. Neste trabalho foi avaliada a influência da incorporação de percentuais de 0,5 e $10 \%$ de óleo de coco em membranas de Celulose Bacteriana (CB). As membranas foram caracterizadas pela técnica de Espectroscopia de Infravermelho (FTIR), Difratometria de Raio-X (DRX) e Análise Termogravimétrica (TGA). Através da técnica de FTIR verificouse a incorporação do óleo de coco na estrutura das membranas de CB. Por meio da análise de DRX percebeu-se que as membranas aditivadas com o óleo de coco apresentaram uma redução no grau de cristalinidade quando comparadas a celulose pura. Através da técnica de TGA verificou-se que a adição do óleo de coco aumentou a estabilidade térmica das membranas, referente ao início de degradação do biopolímero. Por fim, entende-se que as membranas produzidas constituem um material promissor na área de embalagens devido as características acrescentadas pelo óleo de coco à $\mathrm{CB}$ pura.
\end{abstract}

Palavras-chave: Celulose bacteriana; Óleo de coco; Cristalinidade; Estabilidade Térmica.

\begin{abstract}
Bacterial cellulose is an extracellular nanofibrillar polysaccharide that can be produced by acetic bacteria. This biopolymer has excellent characteristics, including high crystallinity, atoxity, high purity, high tensile strength, high water retention capacity, biocompatibility and biodegradability. The addition of vegetable oil in the matrix of this biopolymer appears as a possibility to promote a decrease in crystallinity and expand its applications in the most diverse areas, mainly food and medical-hospital. In this work, the influence of the incorporation of percentages of 0 , 5 and $10 \%$ of coconut oil in Bacterial Cellulose (CB) membranes was evaluated. The membranes were characterized by the technique of Infrared Spectroscopy (FTIR), X-Ray Diffractometry (DRX) and Thermogravimetric Analysis (TGA). Through the FTIR technique, coconut oil was incorporated into the structure of CB membranes. Through $\mathrm{XRD}$ analysis it was noticed that the membranes added with coconut oil showed a reduction in the degree of
\end{abstract}


crystallinity when compared to pure cellulose. Through the TGA technique it was found that the addition of coconut oil increased the thermal stability of the membranes, referring to the beginning of degradation of the biopolymer. Finally, it is understood that the membranes produced are a promising material in the packaging area due to the characteristics added by coconut oil to pure CB.

Keywords: Bacterial cellulose; Coconut oil; Crystallinity; Thermal stability.

\section{Resumen}

La celulosa bacteriana es un polisacárido nanofibrilar extracelular que puede ser producido por bacterias acéticas. Este biopolímero tiene excelentes características, que incluyen alta cristalinidad, atoxidad, alta pureza, alta resistencia a la tracción, alta capacidad de retención de agua, biocompatibilidad y biodegradabilidad. La adición de aceite vegetal en la matriz de este biopolímero aparece como una posibilidad para promover una disminución de la cristalinidad y ampliar sus aplicaciones en las más diversas áreas, principalmente alimentaria y médico-hospitalaria. En este trabajo se evaluó la influencia de la incorporación de porcentajes de 0,5 y $10 \%$ de aceite de coco en membranas de Celulosa Bacteriana (CB). Las membranas se caracterizaron mediante la técnica de Espectroscopia Infrarroja (FTIR), Difractometría de Rayos X (DRX) y Análisis Termogravimétrico (TGA). Mediante la técnica FTIR, el aceite de coco se incorporó a la estructura de las membranas CB. A través del análisis XRD se observó que las membranas añadidas con aceite de coco mostraban una reducción en el grado de cristalinidad en comparación con la celulosa pura. Mediante la técnica TGA se encontró que la adición de aceite de coco incrementó la estabilidad térmica de las membranas, refiriéndose al inicio de la degradación del biopolímero. Finalmente, se entiende que las membranas producidas son un material prometedor en el área de envasado debido a las características que aporta el aceite de coco al CB puro.

Palabras clave: Celulosa bacteriana; Aceite de coco; Cristalinidad; Estabilidad térmica.

\section{Introdução}

A celulose consiste em um polímero com ampla utilização no mundo, podendo ser produzida através de diferentes métodos. As principais fontes de produção são as plantas, porém pode ser sintetizada também por meio de microrganismos, incluindo algas, fungos e bactérias (Uzyol \& Saçan, 2016). A Celulose Bacteriana (CB) é uma forma peculiar de celulose devido as dimensões nanométricas de suas fibras, favorecendo propriedades diferenciadas da Celulose Vegetal (CV) (De Amorim, et al., 2019).

A CB é um polissacarídeo extracelular nanofibrilar excretado pelas células bacterianas, sendo considerada um biopolímero por ser sintetizada através de organismos vivos (Sriplai \& Pinitsoontorn, 2020). Dentre os microrganismos produtores, o mais estudado pertence ao gênero Glucanacetobacter. Estes microrganismos são bacilo aeróbio estrito, Gramnegativo e não patogênico, podendo ser encontrado na natureza em vegetais, frutas e em produtos fermentados (De Amorim, et al., 2019).

A CB apresenta excelentes características, dentre elas tem-se alta cristalinidade, alta pureza, atoxidade, alta resistência à tração, alta capacidade de retenção de água, biodegradabilidade e biocompatibilidade (Silva, et al., 2020). Devido a essas características versáteis e únicas, vem sendo utilizadas em diversas aplicações no campo da medicina (Duarte, et al., 2015), alimentos, farmácia (Tilak, Sanjeev, Marimuthu \& Uthandi, 2020), engenharia (Beekmann, et al., 2020), meio ambiente e moda (Hussain, Sajjad, Khan \& Wahid, 2019).

A Celulose Bacteriana pode ser modificada através da incorporação de substâncias que venham a lhe proporcionar novas características. O óleo de coco é derivado da copra e é composto por uma grande quantidade de lipídeos que apresentam baixo peso molecular (De Pinho \& De Souza, 2018). É composto por ácidos graxos, como o ácido láurico e o cáprico, que possuem grandes potenciais biológicos, como propriedades antifúngicas, antivirais e antimicrobianas (Abllah \& Shahdan, 2018).

Essas propriedades são interessantes para melhorar a conservação de produtos perecíveis através da fabricação de embalagens biodegradáveis e funcionais com a adição de produtos naturais, como por exemplo, extratos vegetais (Carvalho, et al., 2020), óleos essenciais (Costa, et al., 2020), outros polímeros naturais e entre outras tantas possiblidades (Ju, et al., 2020). 
Também pode ser interessante para aplicações biomédicas, onde a CB se sobressai por sua biocompatibilidade (Ullah, et al., 2016).

Neste trabalho foi avaliada a influência da incorporação de percentuais de 0,5 e $10 \%$ de óleo de coco em membranas de Celulose Bacteriana. Foram avaliados o rendimento da produção das membranas, a cristalinidade através da técnica de Difratometria de Raios-X (DRX), os grupos funcionais presentes na estrutura das membranas através da técnica de Espectroscopia de Infravermelho (FTIR) e a estabilidade térmica através da Análise Termogravimétrica (TGA).

\section{Metodologia}

\subsection{Produção e tratamento da Celulose Bacteriana}

\subsubsection{Materiais}

Foi utilizada a bactéria Gluconacetobacter hansenni, depositada no Banco de Culturas da Universidade Católica de Pernambuco, como produtora da CB. Os reagentes peptona, extrato de levedura, $\mathrm{Na}_{2} \mathrm{HPO}_{4}$, ácido cítrico, ágar-ágar e glicose são das marcas Kasvi, Merck, Dinâmica, Dinâmica, Agargel e Neon, respectivamente. O óleo de coco utilizado é da marca Lauricoco.

\subsubsection{Meio de cultura}

O meio de cultura utilizado, tanto para conservação, produção do inóculo como para a produção de CB, foi segundo a composição de Hestrim e Schram (1954). A composição do meio de cultura está descrita na Tabela 1.

Tabela 1 - Composição do meio nutritivo para a manutenção do microrganismo e produção da CB.

\begin{tabular}{cc}
\hline Reagente & Concentração (g/L) \\
\hline Peptona & 5 \\
Extrato de Levedura & 5 \\
$\mathrm{Na}_{2} \mathrm{HPO}_{4}$ & 2,7 \\
Ácido Cítrico & 1,15 \\
Ágar-Ágar & 18 \\
Glicose & 30 \\
\hline
\end{tabular}

Fonte: Hestrim \& Schram (1954).

Através desta tabela é possível observar a composição do meio de cultura, com a concentração em g/L de cada componente. Para a preparação do meio é necessário fazer os cálculos de acordo com o volume de meio utilizado.

\subsubsection{Ativação e propagação da linhagem}

Para a preparação do meio, foram pesados os componentes descritos na Tabela 1 na proporção ideal para o volume de $100 \mathrm{~mL}$ do meio de cultura em um Erlemeyer de $250 \mathrm{~mL}$, para a ativação e manutenção da bactéria. Posteriormente, o meio de cultura foi autoclavado para o processo de esterilização durante o período de 20 min à $121^{\circ} \mathrm{C}$, seguido da adição de Ágar-Ágar. Posteriormente foram adicionados $10 \mathrm{~mL}$ do meio em tubos de ensaio previamente esterilizados e tamponados. Esses tubos foram posicionados inclinados em ângulo de $45^{\circ}$ para ocorrer o processo de solidificação à temperatura ambiente. 
Para o processo de ativação da linhagem, foi transferida uma alçada de células do microrganismo de maneira asséptica e em forma de ziguezague com uma alça de platina para os tubos de ensaio previamente preparados.

Após a realização da repicagem, os tubos foram incubados a $30^{\circ} \mathrm{C}$ por 48 horas em uma estufa. Finalizado esse período de incubação, a linhagem foi mantida refrigerada a $-2^{\circ} \mathrm{C}$, sendo repicada de forma constante para a manutenção das características dos microrganismos (De Vasconcelos, et al., 2020).

\subsubsection{Inóculo e condições de cultivo}

Foram produzidos meios nutritivos líquidos (Tabela 1) em Erlemeyers com capacidade de $250 \mathrm{~mL}$ e volume útil de 50 $\mathrm{mL}$. Nesse sistema foi adicionado $10 \%$ v/v do inóculo e após 20 dias de incubação, as membranas foram retiradas do meio fermentado e purificadas.

\subsubsection{Purificação e Tratamento das membranas}

As películas de CB foram tratadas através de uma lavagem inicial com água destilada e logo após foram imersas em uma solução de $\mathrm{NaOH} 0,1 \mathrm{M}$, e então colocadas em banho maria por um período de $20 \mathrm{~min}$ à $80^{\circ} \mathrm{C}$ (Monteiro, et al., 2018). Em seguida, foram imersas em água destilada durante $24 \mathrm{~h}$ e, logo após, foram submetidas a uma troca de solventes. Foram imersas em soluções de etanol, acetona e clorofórmio, respectivamente, passando um tempo de $24 \mathrm{~h} \mathrm{em}$ cada solvente (Barud, et al., 2011).

\subsubsection{Incorporação do óleo de coco nas membranas}

Após o processo de troca de solventes, as membranas foram pesadas e foram adicionados os percentuais de 5\% e 10\% $\mathrm{m} / \mathrm{m}$ do óleo de coco em relação a massa úmida obtida da película e se aguardou um período de $72 \mathrm{~h}$ para a incorporação do óleo. Em seguida, as membranas foram levadas para a estufa para uma secagem à $60^{\circ} \mathrm{C}$ por aproximadamente $24 \mathrm{~h}$. Após esse período, as membranas foram colocadas em dessecador para estabilização da temperatura e umidade e por fim procedeu-se com as caracterizações necessárias.

\subsection{Caracterizações das membranas}

\subsubsection{Espectroscopia de Infravermelho com Transformada de Fourier (FTIR)}

As membranas foram analisadas pela técnica de Espectroscopia de Infravermelho com Transformada de Fourier com a finalidade de analisar os grupos funcionais dos compostos orgânicos presentes e para verificar a incorporação do óleo de coco. O equipamento utilizado foi da marca Spectrum 400 - Perkin Elmer, utilizando o acessório de Reflectância Total Atenuada (UATR) e está localizado no Laboratório de Combustíveis (LAC) no LitPEG-UFPE. As condições utilizadas foram as seguintes: região do infravermelho na faixa de 550 a $4000 \mathrm{~cm}^{-1} \mathrm{e}$ resolução de $4 \mathrm{~cm}^{-1} \mathrm{e}$ acessório ATR.

\subsubsection{Difratometria de Raios X (DRX)}

Visando a identificação das fases cristalinas foram realizadas análises de difratometria de raios $\mathrm{X}$ nas membranas utilizando um difratômetro da Rigaku com tubo de cobre aplicado com tensão de $40 \mathrm{kVe}$ e corrente de $20 \mathrm{~mA}$ na escala de $2 \theta$ com intervalo de $5^{\circ}$ a $55^{\circ}$ com velocidade de varredura de $0,5 \%$ min. Para o cálculo do percentual de celulose cristalina $(\% \mathrm{C})$ foi utilizada a Equação 1. O cálculo é baseado na diferença entre os picos de maior e menor intensidade, que correspondem de maneira respectiva aos picos cristalinos (Ic) e amorfos (Ia).

$$
\% C=\frac{I c-I a}{I c} \times 100 \quad \text { Equação } 1
$$




\subsubsection{Análise Termogravimétrica (TGA)}

As membranas foram analisadas por análise termogravimétrica com a finalidade de avaliar as taxas de perda de massa. Foram pesadas aproximadamente $20 \mathrm{mg}$ de cada amostra e estas foram introduzidas em um equipamento da marca METTLER TOLEDO TGA 2 Star System. As análises foram realizadas a uma faixa de temperatura de 30 a $800^{\circ} \mathrm{C}$, com taxa de aquecimento de $10^{\circ} \mathrm{C} / \mathrm{min}$ sob atmosfera de nitrogênio.

\section{Resultados e Discussão}

\subsection{Produção de Celulose Bacteriana}

Foram produzidas membranas de celulose bacteriana para cada percentual de óleo de coco. Na Tabela 2, é apresentado os resultados referentes aos rendimentos da celulose com 0,5 e $10 \% \mathrm{~m} / \mathrm{m}$ de óleo de coco em relação aos seus pesos úmidos e secos. Quando se compara as massas úmidas e secas, verifica-se que houve uma grande redução nos valores, isso pode ser atribuído a grande capacidade de absorção de água pelas membranas de celulose bacteriana.

Tabela 2 - Resultados dos rendimentos das massas úmidas e secas da celulose bacteriana.

\begin{tabular}{cccc}
\hline Membrana & Massa úmida $(\mathbf{g} / \mathbf{L})$ & Massa seca $(\mathbf{g} / \mathbf{L})$ & Perda de água $(\%)$ \\
\hline Celulose + 0\% óleo & 485,85 & 9,06 & 98,13 \\
Celulose + 5\% óleo & 682,87 & 14,63 & 97,86 \\
Celulose + 10\% óleo & 700,76 & 16,2 & 97,68 \\
\hline
\end{tabular}

Fonte: Autores.

Através da Tabela 2 é possível observar os valores da massa úmida, massa seca e o percentual de perda de água para a celulose bacteriana. É perceptível que a perda é maior para a membrana pura. De Morais Câmpelo (2017) em seu estudo, verificou um percentual de perda de água de 95,57\% para membranas de CB utilizando o meio salino, valor bem próximo ao obtido nesse trabalho.

\subsection{Espectroscopia de Infravermelho com Transformada de Fourier}

Essa técnica possui a capacidade de identificar grupos funcionais pertencentes a uma substância, revelando as informações detalhadas sobre a estrutura química do material (Skoog, 2002). Na Tabela 3 estão apresentadas as principais bandas vibracionais características no espectro de infravermelho para as membranas de Celulose Bacteriana. 
Tabela 3 - Atribuições das bandas características no espectro de infravermelho da Celulose Bacteriana.

\begin{tabular}{cc}
\hline $\begin{array}{c}\text { Número de onda Celulose Bacteriana } \\
\left(\mathbf{c m}^{-\mathbf{1}}\right)\end{array}$ & Atribuições \\
\hline $3690-2981$ & Estiramento OH \\
$2974-2831$ & Estiramento CH \\
$1652-1647$ & Estiramento COO assimétrico \\
$1414-1412$ & Estiramento COO simétrico \\
$1030-1028$ & Estiramento de vibração do anel aromático (COC, COH) \\
\hline
\end{tabular}

Fonte: Autores.

Essas bandas vibracionais podem ser observadas na Figura 1, que apresenta os espectros de infravermelho das membranas de Celulose Bacteriana incorporadas com 0\%, 5\% e 10\% de óleo de coco.

Figura 1 - Espectros de Infravermelho das membranas de Celulose Bacteriana incorporadas com óleo de coco.

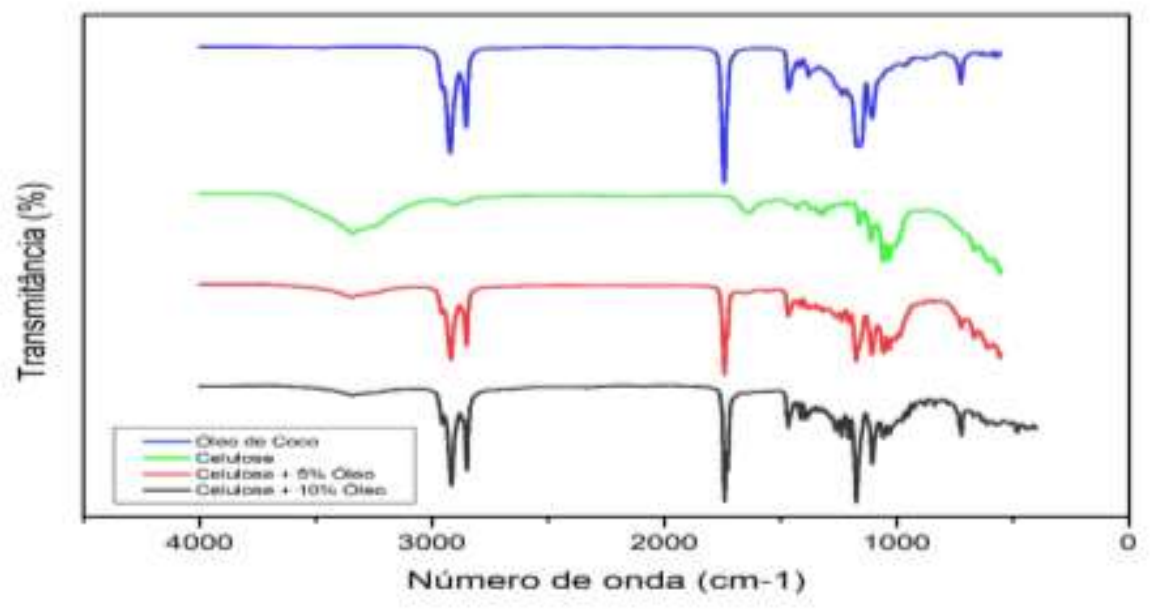

Fonte: Autores.

Através da Figura 1 é possível analisar as bandas vibracionais da celulose pura, aditivada com 5\%, 10\% de óleo de coco e também a estrutura do óleo puro. Observa-se que a celulose pura apresentou os picos característicos do polímero, observando-se uma larga banda de adsorção na faixa de 3300 aproximadamente, estando relacionada com o estiramento dos grupos $\mathrm{OH}$. Observa-se também a presença da carboxila na banda correspondente a $1641 \mathrm{~cm}^{-1}$.

As membranas com incorporação do óleo de coco apresentaram as bandas características do óleo, com picos intensos nas bandas de 1900-1800 $\mathrm{cm}^{-1}$ e em $1746 \mathrm{~cm}^{-1}$, indicando que ocorreu a incorporação do óleo na estrutura do polímero. Observa-se também que os espectros das membranas com $5 \%$ e $10 \%$ do óleo de coco apresentarem-se semelhantes, alterando apenas a intensidade dos picos.

O óleo de coco apresenta em sua estrutura uma predominância de ácidos graxos de cadeia média, correspondendo a 70-80\% de sua composição, sendo os mais predominantes o ácido láurico (46\%), o ácido mirístico (18\%) e o ácido palmítico (9\%) (Martins \& Santos, 2015). Através do espectro de infravermelho apresentado na Figura 1, foi possível observar as bandas características desses componentes, sendo observado uma banda muito forte do grupo $\mathrm{C}=\mathrm{O}$ que aparece entre 1730 e 1700 e 
também observa-se o estiramento $\mathrm{OH}$ que vai de 3000-2800, o estiramento C-O é observado na faixa de 1330 a 1225 , com intensidade média, sendo esses picos característicos de um ácido carboxílico.

\subsection{Difratometria de Raios $X$}

Essa técnica foi utilizada para analisar a cristalinidade das membranas obtidas. A celulose bacteriana consiste em um biopolímero que apresenta estrutura semicristalina, estando presente em sua estrutura duas fases cristalinas: I $\alpha$ e I $\beta$, correspondendo de forma respectiva às estruturas triclínica e monoclínica (Atalla \& Vanderhart, 1984).

A Figura 2 ilustra os difratogramas obtidos para as membranas de celulose bacteriana aditivadas com 0,5 e $10 \% \mathrm{~m} / \mathrm{m}$ de óleo de coco representadas por celulose pura, celulose $+5 \%$ óleo e celulose $+10 \%$ óleo, respectivamente.

Figura 2 - Difratogramas das membranas de Celulose Bacteriana com diferentes percentuais de óleo de coco.

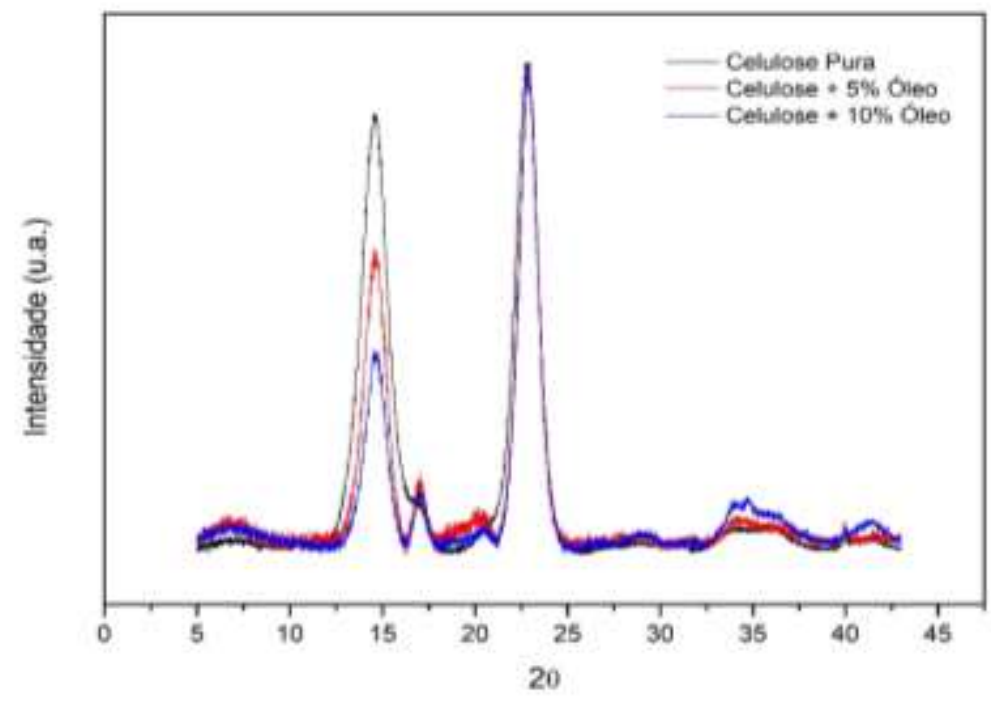

Fonte: Autores.

Analisando a Figura 2, pode-se observar que os picos obtidos foram largos, característica de um material semicristalino. Observa-se também a existência de picos de difração $2 \theta$ em $14,2^{\circ}, 16,5^{\circ}$ e $22,3^{\circ}$, sendo estes associados à distância entre os planos cristalográficos das fases da estrutura cristalina. Pode-se reparar também uma variação das intensidades dos picos devido aos diferentes percentuais do óleo na $\mathrm{CB}$, obtendo diferentes graus de cristalinidade.

Através da metodologia de Segal, Creely, Martin Jr e Conrad (1959), os percentuais de cristalinidade foram obtidos, sendo correspondentes a 78,27\%, 67\% e 55,30\% para as membranas de celulose aditivadas com 0, 5 e 10\% m/m do óleo de coco, respectivamente.

Segundo a literatura, a celulose bacteriana apresenta alto grau de cristalinidade, sendo entre 60 a $90 \%$ (Das Chagas, 2018). Através da Figura 1, verifica-se que a membrana com $0 \%$ de óleo de coco está dentro dessa faixa. Foi verificado também que incorporação do óleo de coco afetou o grau de cristalinidade da membrana. O aumento percentual de óleo de coco na matriz polimérica ocasiona uma redução da cristalinidade. Isso pode ser atribuído a conversão de regiões mais ordenadas do polímero em regiões mais desordenadas (Castellões, 2016). 


\subsection{Análise Termogravimétrica (TGA)}

O termograma das membranas produzidas está representado na Figura 3. Todas as amostras analisadas apresentaram três estágios de degradação.

Figura 3 - Termograma das membranas de Celulose Bacterianas aditivadas com 0\%, 5\% e 10\% de óleo de coco.
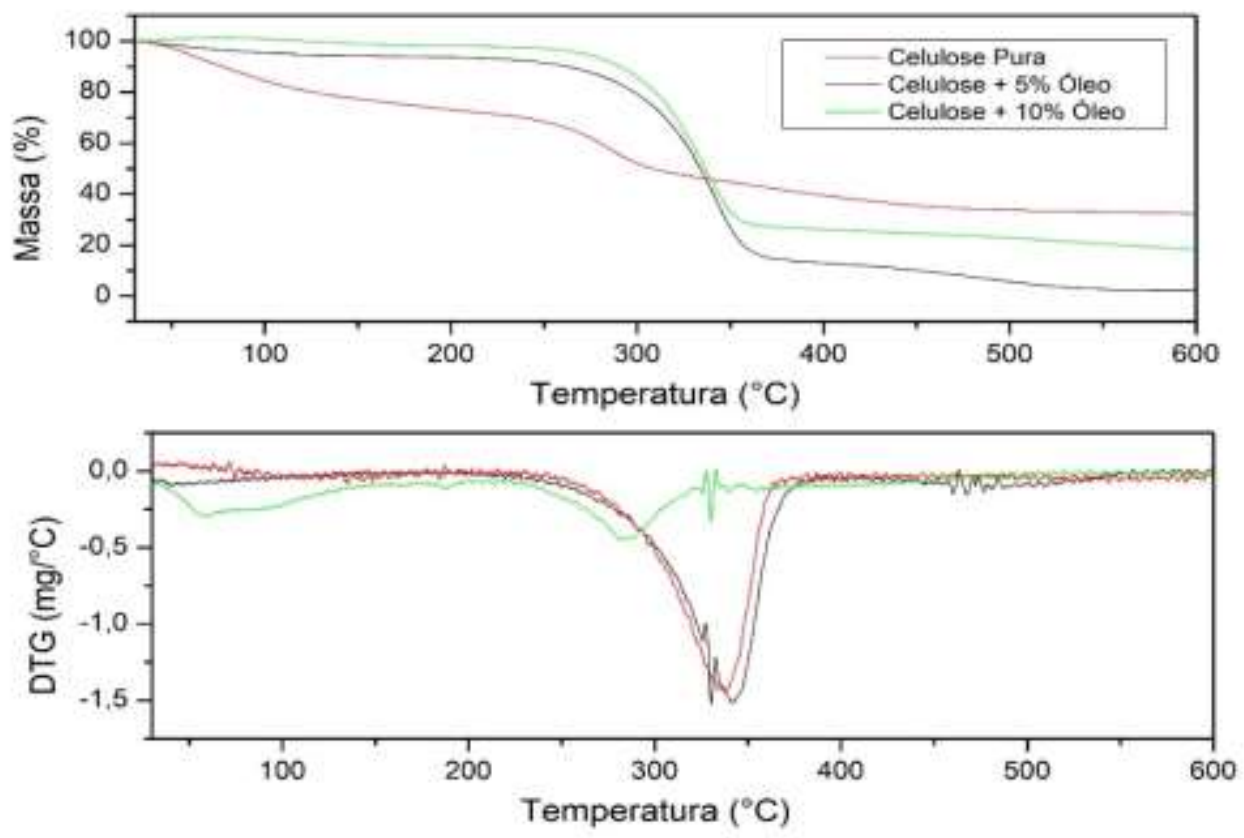

Fonte: Autores.

De acordo com a Figura 3 é possível observar com o gráfico da DTG que a membrana de CB pura apresentou 3 estágios de perda de massa. O primeiro em temperaturas próximas de $100^{\circ} \mathrm{C}$, correspondendo ao processo de perda de umidade, o segundo em torno de $230^{\circ} \mathrm{C}$ a $350^{\circ} \mathrm{C}$, correspondendo à faixa degradativa e o terceiro com temperaturas acima de $350^{\circ} \mathrm{C}$, correspondendo ao processo de degradação termo-oxidativa. No caso das membranas aditivadas com o óleo de coco, foi possível observar também três estágios de degradação. Os resultados referentes às temperaturas de degradação estão expostos na Tabela 4.

Tabela 4 - Temperaturas de degradação para as membranas de CB aditivadas com 0\%, 5\% e 10\% de óleo de coco.

\begin{tabular}{lccccccc}
\hline Amostras & \multicolumn{3}{c}{$\mathbf{1}^{\circ}$ Estágio } & \multicolumn{5}{c}{$\mathbf{2}^{\circ}$ Estágio } & $\mathbf{3}^{\circ}$ Estágio \\
\hline & $\mathrm{T}_{\text {on }}$ & $\mathrm{T}_{\text {off }}$ & $\mathrm{T}_{\text {máx }}$ & $\mathrm{T}_{\text {on }}$ & $\mathrm{T}_{\text {off }}$ & $\mathrm{T}_{\text {máx }}$ & Temperatura \\
Celulose & 30,2 & 146,1 & 58,4 & 224,3 & 354,0 & 283,8 & $>350$ \\
$\quad$ Pura & & & & & & & \\
$\begin{array}{c}\text { Celulose + } \\
\text { 5\% Óleo }\end{array}$ & 30,2 & 159,5 & - & 259,2 & 367,4 & 341,5 & $>350$ \\
$\begin{array}{c}\text { Celulose + } \\
10 \% \text { Óleo }\end{array}$ & 30,2 & 156,2 & - & 259,3 & 357,8 & 335,9 & $>350$ \\
\hline
\end{tabular}


Através da Tabela 4 é possível observar que a adição do óleo de coco melhorou a estabilidade térmica da membrana de CB. Isso pode ser observado no segundo estágio, correspondendo à degradação térmica da celulose, em que se percebe que as temperaturas iniciais de degradação para as membranas aditivadas com o óleo apresentaram-se maiores que a da celulose pura, indicando uma maior estabilidade térmica.

Analisando os termogramas, observa-se uma perda de massa em temperaturas próximas de $100^{\circ} \mathrm{C}$, estando relacionadas à perda de umidade. As perdas de massa foram correspondentes a 21,74\%, 5,9\% e 0,64\% para as amostras de celulose com $0 \%, 5 \%$ e $10 \%$ de óleo de coco respectivamente, conforme a Tabela 5.

Tabela 5 - Dados da avaliação termogravimétrica.

\begin{tabular}{ccccc}
\hline & \multicolumn{3}{c}{ Perda de massa (\%) } & Resíduo Final \\
\hline Amostra & Perda de umidade & Faixa degradativa & $\begin{array}{c}\text { Degradação termo- } \\
\text { oxidativa }\end{array}$ \\
Celulose Pura & 21,74 & 26,76 & 12,3 & 31,9 \\
Celulose + 5\% & 5,9 & 74,63 & 12,37 & 2,5 \\
Óleo & 0,64 & 68,73 & 9,71 & 18,4 \\
Celulose $+10 \%$ & & & \\
Óleo & & & \\
\hline
\end{tabular}

Fonte: Autores.

Observa-se através da Tabela 5 que quanto maior o percentual de óleo de coco, menor a quantidade de água perdida. Isso pode ter ocorrido devido a troca de solventes realizada para as amostras que foram incorporadas com o óleo, diminuindo assim o teor de umidade das membranas secas. Outro fator que pode ter alterado é a diferença de cristalinidade das membranas.

\section{Conclusão}

De acordo com os resultados obtidos, foi possível verificar através da Espectroscopia de Infravermelho que houve a incorporação do óleo de coco nas membranas aditivas, pois as mesmas apresentaram os grupos funcionais característicos do óleo. Através da técnica de DRX foi possível verificar que as membranas aditivadas com o óleo de coco apresentaram uma redução no grau de cristalinidade quando comparadas a celulose pura. Essa redução na cristalinidade indica que o óleo de coco exerceu influência na estrutura molecular da CB. Através da técnica de TGA foi possível verificar que a adição do óleo de coco aumentou a estabilidade térmica dos filmes. Sendo assim, foi possível produzir neste estudo membranas com propriedades atrativas, podendo ser indicadoras para aplicações nas áreas alimentícias como embalagem para alimentos e hospitalares.

Como sugestões para trabalhos futuros, é interessante a realização de análises de atividade antimicrobiana nas membranas aditivadas com o óleo de coco e no óleo puro, tendo em vista que na literatura o óleo apresenta propriedades antifúngicas, antivirais e antimicrobianas. É importante também a realização de ensaios mecânicos nas amostras, pois a adição do óleo apresentou uma alteração na textura dos filmes, o que poderá ter resultado em alterações em suas propriedades mecânicas, como por exemplo, resistência mecânica. 


\section{Referências}

Abllah, Z., \& Shahdan, I. (2018). Virgin Coconut Oil and Its Antimicrobial Properties against Pathogenic Microorganisms: A Review. Advances in Health

Science Research, 8, 191-199.

Atalla, R. H., \& Vanderhart, D. L. (1984). Native Cellulose: A Composite of Two Distinct Crystalline Forms. Science, 223(4633), $283-285$.

Barud, H. S., Souza, J.L., Santos, D. B., Crespi, M. S., Ribeiro, C. A., Messaddeq, Y., Ribeiro, S. J. L. (2011). Bacterial cellulose/poly(3-hydroxybutyrate) composite membranes. Carbohydrate Polymers, 83, 1279-1284.

Beekmann, U.; Schmölz, L.; Lorkowski, S.; Werz, O.; Thamm, J.; Fischer, D.; Kralisch, D. (2020). Process control and scale-up of modified bacterial cellulose production for tailor-made anti-inflammatory drug delivery systems. Carbohydrate Polymers, 236(116062), 1-10.

Carvalho, F. M.; Martins, J. T. A.; Lima, E. M. F.; Santos, H. V.; Pereira, P. A. P.; Pinto, U. M.; Cunha, L. R. (2020) Pitanga and grumixama extracts: antioxidant and antimicrobial activities and incorporation into cellulosic films against Staphylococcus aureus. Research, Society and Development, 9(11), 1-24.

Castellões, F. R. L. (2016). Estudo das condições de processamento e caracterização da matéria prima para a produção de um biocompósito de matriz de poli(succinato de butileno) com reforço de celulose branqueada. Trabalho de Conclusão de Curso. Centro Federal de Educação Tecnológica de Minas Gerais, Belo Horizonte, MG, Brasil.

Costa, A. L. R.; Oliveira, A. C. S.; Azevedo, V. M.; Medeiros, E. A. E.; Soares, N. F. F.; Borges, S. V. (2020) Essentials oils of garlic and orégano incorporated in cellulose acetate films: antimicrobial activity and physical properties. Research, Society and Development, 9(10).

Das Chagas, B. S. (2018). Produção de celulose bacteriana em meio à base de melaço de soja em cultivo estático. Dissertação de Mestrado. Universidade Federal do Ceará, Fortaleza, CE, Brasil.

De Amorim, J. D. P., Da Silva Júnior, C. J. G., Costa, A. F. S., De Melo, J. F. H., \& Sarubbo, L. A. (2019). Avaliação do potencial da celulose bacteriana para aplicação em cosméticos. Brazilian Journal of Development, 5(10), 18457-18462.

De Morais Câmpelo, J. (2017). Produção de celulose bacteriana em meio de glicerol. Dissertação de Mestrado. Universidade Federal e Pernambuco, Recife, PE, Brasil.

De Vasconcelos, G. M. D.; De Souza, K. C.; Silva, I. D. L.; Silva, A. C. P. F., Vinhas, G. M. (2020). Production and characterization of cellulose by Glucanoacetobacter hansenii in medium containing glucose or mannitol. Revista Matéria, 25(4).

Duarte, E. B.; das Chagas, B. S.; Andrade, F. K.; Brígida, A. I. S.; Borges, M. F.; Muniz, C. R.; Filho, M. S. M. S.; Morais, J. P. S.; Feitosa, J. P. A.; Rosa, M. F. (2015). Production of hydroxyapatite-bacterial cellulose nanocomposites from agroindustrial wastes. Cellulose, 22, 3177-3187.

Hussain, Z., Sajjad, W., Khan, T., \& Wahid, F. (2019). Production of bacterial cellulose from industrial wastes: a review. Cellulose, 26, $2895-2911$.

Ju, S.; Zhang, F.; Duan, J.; Jiang, J. (2020). Characterization of bacterial cellulose composite films incorporated with bulk chitosan and chitosan nanoparticles: A comparative study. Carbohydrate Polymers, 237(116167), 1-8.

Monteiro, A. S., Domeneguetti, R. R., Wong Chi Man, M., Barud, H. S., Teixeira-Neto, E., \& Ribeiro, S. J. L. (2018). Membranas híbridas de celulose bacteriana-SiO2 @ TiO2 orgânica-inorgânica com propriedades de autolimpeza. Journal of Sol-Gel Science and Technology.

Pinho, A. P. S., \& Souza, A. F. (2018). Extração e caracterização do óleo de coco (cocos nucifera 1.). Perspectivas Online: Biológicas \& Saúde, 8(26), 9-18.

Segal, L., Creely, J.J., Martin Jr., A.E., \& Conrad, C.M. (1959). An Empirical Method for Estimating the Degree of Crystallinity of Native Cellulose Using the X-Ray Diffractometer. Textile Research Journal, 29, 786-794.

Silva, J. G. M.; Pinto, F.C.; Oliveira, G. M.; Silva, A. A.; Júnior, O. C.; Silva, R. O.; Teixeira, V. W.; Melo, I. M. F.; Paumgartten, F. J. R.; Souza, T. P.; Carvalho, R. R.; Oliveira, A. C. A. X.; Aguiar, J. L. A.; Teixeira, A. A. C. (2020) Non-clinical safety study of sugarcane bacterial cellulose hydrogel. Research, Society and Development, 9 (9), 1-23.

Sriplai, N., \& Pinitsoontorn, S. (2020). Bacterial Cellulose-based Magnetic Nanocomposites: A Review. Carbohydrate Polymers, 254(117228), 1-55.

Skoog, D. A., Holler, F. J., Nieman, T. A. (2002). Princípios de análise instrumental. 5. Ed. Bookman.

Tilak, J., Sanjeev, B., Marimuthu, S., \& Uthandi, S. (2020). Bacterial Cellulose Nano Fiber (BCNF) as carrier support for the immobilization of probiotic, Lactobacillus acidophilus 016. Carbohydrate Polymers, 250(116965), 1-8.

Ullah, H.; Wahid, F.; Santos, H. A.; Khan, T. (2016). Advances in biomedical and pharmaceutical applications of functional bacterial cellulose-based nanocomposites. Carbohydrate Polymers, 150, 330-352.

Uzyol, H. K., \& Saçan, M. T. (2016). Bacterial cellulose production by Komagataeibacter hansenii using algae-based glucose. Environmental Science and Pollution Research, 24(12), 11154-11162. 